\section{World TB Day — March 24, 2020}

World TB Day is observed each year on March 24, providing an opportunity to increase awareness about tuberculosis (TB) and the actions needed to find, treat, and prevent this devastating disease.

In 2019, a provisional total of $8,920 \mathrm{~TB}$ cases were reported in the United States (incidence $=2.7$ cases per 100,000 persons) $(I)$, a 1.1\% decrease from the 9,021 cases reported during 2018 and the lowest number of U.S. cases recorded since reporting began in 1953. Increased diagnosis and treatment of latent TB infection remains essential for eliminating TB in the United States.

An analysis of global TB surveillance data found that in 2018, an estimated 10 million persons with incident TB and 1.5 million TB-related deaths occurred worldwide, representing 2\% and 5\% declines from 2017. Among the estimated 10 million persons with TB, 70\% were reported to $\mathrm{WHO}$ in 2018, a 9.4\% increase from 2017 (2). Approximately 862,000 reported TB cases occurred among persons living with human immunodeficiency virus (HIV) infection. In 2018, 1.8 million persons with HIV began TB preventive treatment (TPT), a $88 \%$ increase in treatment initiation from 2017. Less progress in TPT implementation was reported among children aged $<5$ years than among persons living with HIV infection. TPT has been demonstrated to decrease morbidity and mortality among persons with HIV infection. Full implementation of effective strategies, including TPT, is crucial for reaching global targets.

$\mathrm{CDC}$ is working with partners to diagnose, treat, and prevent TB in the United States and globally. Additional information is available at https://www.cdc.gov/tb/worldtbday/ and https://www.cdc.gov/globalhivtb/who-we-are/ events/world-tb-day/worldtbday.html.

\section{References}

1. Schwartz NG, Price SF, Pratt RH, Langer AJ. Tuberculosis-United States, 2019. MMWR Morb Mortal Wkly Rep 2020;69:286-90.

2. MacNeil A, Glaziou P, Sismanidis C, et al. Global epidemiology of tuberculosis and progress toward meeting global targets - worldwide, 2018. MMWR Morb Mortal Wkly Rep 2020;69:281-5.

\section{Global Epidemiology of Tuberculosis and Progress Toward Meeting Global Targets — Worldwide, 2018}

Adam MacNeil, $\mathrm{PhD}^{1}$; Philippe Glaziou, $\mathrm{MD}^{2}$; Charalambos Sismanidis, $\mathrm{PhD}^{2}$; Anand Date, $\mathrm{MD}^{1}$; Susan Maloney, $\mathrm{MD}^{1}$; Katherine Floyd, $\mathrm{PhD}^{2}$

Worldwide, tuberculosis (TB) is the leading cause of death from a single infectious disease agent (1), including among persons living with human immunodeficiency virus (HIV) infection (2). A World Health Organization (WHO) initiative, The End Tuberculosis Strategy, set ambitious targets for 2020-2035, including 20\% reduction in TB incidence and $35 \%$ reduction in the absolute number of TB deaths by 2020 and $90 \%$ reduction in TB incidence and $95 \%$ reduction in TB deaths by 2035, compared with 2015 (3). This report evaluated global progress toward these targets based on data reported by

\section{INSIDE}

286 Tuberculosis — United States, 2019

290 Drug and Opioid-Involved Overdose Deaths United States, 2017-2018

298 Variation in Adult Outpatient Opioid Prescription Dispensing by Age and Sex — United States, 2008-2018

303 Delayed Identification of Infants Who Are Deaf or Hard of Hearing - Minnesota, 2012-2016

307 Evaluation of the Effectiveness of Surveillance and Containment Measures for the First 100 Patients with COVID-19 in Singapore - January 2February 29, 2020

312 Initial Investigation of Transmission of COVID-19 Among Crew Members During Quarantine of a Cruise Ship - Yokohama, Japan, February 2020

314 QuickStats

Continuing Education examination available at https://www.cdc.gov/mmwr/mmwr_continuingEducation.html

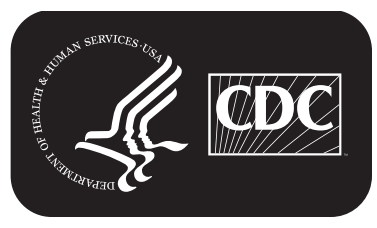

U.S. Department of Health and Human Services Centers for Disease Control and Prevention 